\title{
ETNOBOTÂNICA DE PLANTAS MEDICINAIS NA COMUNIDADE DE VÁRZEA IGARAPÉ DO COSTA, SANTARÉM-PARÁ, BRASIL
}

\author{
Ethnobotany of Medicinal Plants in the Low \\ Land Community Igarapé do Costa, Santarém-Pará, Brazil
}

JÉSSICA PALOMA GAMA DOS SANTOS-SILVA", PATRÍCIA CHAVES DE OLIVEIRA ${ }^{2}$

1Bacharelado em Biotecnologia, Instituto de Biodiversidade e Florestas, Universidade Federal do Oeste do Pará. 2Instituto de Biodiversidade e Florestas, Universidade Federal do Oeste do Pará.

E-mail: jessicapalloma@yahoo.com.br

lab.estudosamazonicos@gmail.com

Recibido: 16 de Agosto de 2016

Aceptado: Noviembre 3 de 2016

\begin{abstract}
Resumen
As comunidades rurais de várzea localizadas na Amazônia possuem enorme valor cultural no que tange a etnobotânica, pois faz com que o conhecimento tradicional dessas populações seja resguardado e pode permitir a descoberta de novos fármacos advindos de plantas medicinais. A pesquisa etnobotânica foi aplicada na comunidade de Igarapé do Costa, que se localiza na cidade de Santarém, no estado do Pará, Brasil $\left(02^{\circ} 15^{\prime} 11^{\prime \prime}\right.$ Sul e $54^{\circ} 38^{\prime} 40^{\prime \prime}$ Oeste). O questionário possuía questões socioeconômicas e perguntas específicas sobre plantas medicinais como formas de uso, partes utilizadas etc. A faixa de idade mais expressiva entre os entrevistados foi de 25 a 35 anos, as mulheres possuíram maior representatividade na entrevista com $92 \%, 67 \%$ dos entrevistados são pescadores, 33\% possuem o fundamental completo e $75 \%$ moram a vida toda na comunidade. A parte mais utilizada das plantas foi a folha, o chá preparado a partir das folhas foi a forma de uso mais expressiva. As espécies com maior número de citações foram: Folha-grossa (Plectranthus amboinicus (Lour.) Spreng), Cidreira (Lippia alba (Mill.) N. E. Br.), Arruda (Ruta graveolens.), Cumarú (Dipteryx odorata (Aubl.) Willd) e Sara-tudo (Justicia acuminatissima (Miq.) Bremek.). As comunidades ribeirinhas são um rico repositório de conhecimento, a relação do homem com o rio, a fauna e a flora do ecossistema revela a importância de se fazer pesquisas etnobotânicas com este tipo de comunidade, com vistas a trazer retornos para eles próprios e para a população mundial.
\end{abstract}

Palabras claves: Etnobotânica, Ribeirinhos, Várzeas, Plantas medicinais.

\section{Abstract}

Rural lowland communities located in the Amazon have huge cultural value in relation to ethnobotany, because it makes the traditional knowledge of these populations be safeguarded and can enable the discovery of new drugs arising from medicinal plants. The ethnobotanical survey was conducted in community Igarapé do Costa, which is located in the city of Santarém, in Pará State, Brazil (02 ${ }^{\circ} 15^{\prime} 11^{\prime \prime S o u t h}$ and $54^{\circ} 38^{\prime} 40^{\prime \prime}$ West). The questionnaire had socio-economic issues and specific questions about medicinal plants as forms of use, parts used etc. The range of more expressive age among respondents was $25-35$ years, women possessed greater representation in the interview with $92 \%, 67 \%$ of respondents are fishermen, 33\% have completed primary and $75 \%$ live the life in the community. The most used part of plants was the leaf tea prepared from the leaves was more significant form of use. The species with the highest number of citations were: Folha-grossa (Plectranthus amboinicus (Lour) Spreng.), Cidreira (Lippia alba (Mill) N. E. Br.), Arruda (Ruta graveolens), Cumarú (Dipteryx odorata (Aubl). Willd) and Sara-tudo (Justicia acuminatissima (Miq.) Bremek.). Riverine communities are a rich repository of knowledge and man's relationship with the river, fauna and ecosystem flora reveals the importance of doing ethnobotanical research with this type of community, in order to bring returns for themselves and for world population.

Keywords: Ethnobotany, Riparian, Wetlands, Medicinal plants. 


\section{INTRODUÇÃO}

A várzea é um ecossistema acometido por um período de inundação seguido por um período de seca ao longo do ano. A fase aquática pode durar cerca de 6 meses e neste período o rio chega a ficar de 7 a 15 metros acima do nível do mar (Cavalcante 2014). No entanto, dados divulgados na cartilha Testemunhas do Clima: comunidade Igarapé do Costa Várzea de Santarém, PA, publicada pelo Instituto de Pesquisa Ambiental da Amazônia no ano de 2008, apontam que, nos últimos anos, as enchentes estão se iniciando mais cedo, a fase aquática tem tido maior duração que a fase terrestre e o rio tem chegado a níveis mais altos. O tipo de rio que banha as várzeas, o rio de água branca, também caracteriza seu solo como fértil e propício para o cultivo, por conta das aluviões em suspensão na água que são depositados no solo durante a vazante (Prance 1980). Os sedimentos trazidos pela água durante a cheia fertilizam o solo, porém, também asfixiam, determinando que apenas espécies vegetais adaptadas a este fenômeno permaneçam. Algumas espécies medicinais ou condimentares, mesmo as cultivadas e conhecidas neste ecossistema, só são possíveis de produzir em vasos elevados, em canteiros ou dentro das casas.

O Decreto $N^{\circ}$ 6.040, de 7 de Fevereiro de 2007, que institui a Política Nacional de Desenvolvimento Sustentável dos Povos e Comunidades Tradicionais, caracteriza povos e comunidades tradicionais como grupos culturalmente diferenciados e que se reconhecem como tais, que possuem formas próprias de organização social, que ocupam e usam territórios e recursos naturais como condição para sua reprodução cultural, social, religiosa, ancestral e econômica, utilizando conhecimentos, inovações e práticas gerados e transmitidos pela tradição.

Em se tratando de comunidades tradicionais, os ribeirinhos possuem grande valor cultural, por conta de sua estreita relação com o meio em que vivem, sendo que este é um ambiente bastante versátil, e que exige que os organismos que se estabelecem nele sejam versáteis também. Por esse motivo, as várzeas e as populações que nela habitam tornam-se cada vez mais alvos de pesquisas, onde procurase entender principalmente a relação homem/natureza nesse ecossistema, sabendo-se que a variação anual que ocorre nos rios das várzeas tem grande influência nessa relação e também na relação ribeirinho/políticas públicas.

Ao se caracterizar povos e comunidades tradicionais como grupos diferenciados, podemos concluir também que as políticas públicas para estas comunidades também devam ser diferenciadas e respeitem suas especificidades, porém o isolamento geográfico em que se encontram as comunidades ribeirinhas, e a dificuldade de locomoção dessas pessoas faz com que haja barreiras entre elas e os serviços públicos, em especial aos de saúde e saneamento (Moura 2009). O que se percebe é que os indicadores que qualificam o modo de vida ribeirinho são baseados na perspectiva urbana, e não levam em conta as características particulares da relação da população com o ecossistema em que estão inseridos, ou seja, desconsideram a interferência ambiental na saúde das comunidades de várzea. Além disso, atividades econômicas desenvolvidas em ecossistemas de várzea (como a pesca, agricultura e pecuária) ainda de forma arcaica, levam riscos à saúde e à vida dessa população, bem como a precariedade do saneamento básico e disponibilidade de água (Moura 2009).

Na comunidade de várzea que foi objeto de estudo desta pesquisa, Igarapé do Costa, durante a cheia, a água para consumo, é retirada das redondezas das casas, próximo de onde é despejada a água das privadas. Algumas casas possuem filtros, porém a água que é consumida na comunidade, além de ser a água branca do rio Amazonas, não passa pelo devido tratamento para que seja considerada potável, tornando as verminoses e doenças estomacais um problema recorrente na comunidade. Além disso, um problema grandemente relatado pelos comunitários na época da cheia são os problemas respiratórios, devido à alta humidade do ar.

Sabe-se que as comunidades que se estabeleceram em regiões como as várzeas, passaram a ter uma conexão muito forte com o ecossistema, passando a conhecê-lo e explorá-lo da melhor forma encontrada por eles. É o caso do conhecimento etnobotânico, que é adquirido tanto com a experiência quanto com a transmissão cultural verbal, que se refere ao conhecimento passado de uma geração a outra, e que desempenha um papel histórico importante pois facilita a sobrevivência humana no decorrer destas gerações (Martínez-Rodrígues 2009). A cultura é um fator que determina, entre outas coisas, o comportamento humano em relação à saúde, e a transmissão de conhecimentos sobre o uso de recursos vegetais disponíveis em cada região tem sido uma função da cultura, sendo este conhecimento específico para cada tipo de comunidade. Portanto, o saber local etnobotânico é de extrema importancia para muitos aspectos como saúde e alimentação em areas rurais de baixa renda, porém este conhecimento vem sendo afetado e ameaçado pelo advento da globalização (McDade et al. 2007).

Mesmo com a distância das várzeas para os centros urbanos e com necessidades ainda muito grandes de acesso à saúde destas comunidades o que se percebe é que o conhecimento sobre as plantas medicinais vem decrescendo com o tempo, ocasionado principalmente pelo êxodo rural, o desinteresse 
das gerações mais novas por esse aprendizado e a modernização e urbanização (Freitas et al. 2012), que vem levando essas comunidades a esperar sempre por remédios industrializados que devem ser disponibilizados pelos órgãos públicos. No entanto, essa distribuição não é feita de maneira efetiva. No centro de saúde da comunidade Igarapé do Costa, os remédios disponibilizados pelos órgãos de saúde são os mais básicos possíveis. Em casos de mordida de cobra, por exemplo, que é algo muito comum já que se trata de uma região conhecida por possuir muitas cobras venenosas, o comunitário teria que se dirigir aos centros de saúde da cidade de Santarém para ser medicado, pois o soro antiofídico não é disponibilizado para essa comunidade.

A Organização Mundial de Saúde (OMS), em 1978, reconheceu o uso de remédios à base de plantas e difundiu mundialmente os saberes necessários para o seu uso, inserindo o Brasil, alguns anos depois na discussão dos produtos fitoterápicos e medicina tradicional por conta de a maior diversidade genética vegetal estar situada no país (principalmente na Amazônia) e pelo histórico de uso e conhecimento dos povos tradicionais sobre o assunto (Ministério da Saúde et al. 2006a). No Brasil, por meio do Decreto $n^{\circ}$ 5.813, de 22 de Junho de 2006, o Governo Federal aprovou a Política Nacional de Plantas Medicinais e Fitoterápicos, com o intuito de criar um Grupo de Trabalho Interministerial juntamente com membros da sociedade civil para a elaboração do Programa Nacional de Plantas Medicinais e Fitoterápicos (Ministério da Saúde et al. 2006b), pautado na ampliação das opções terapêuticas e melhoria da atenção ao usuários da saúde pública, manejo sustentável da biodiversidade brasileira, preservação do saber tradicional das populações, geração de renda etc. (Ministério da Saúde et al. 2009).

Portanto, é de extrema importância a realização de estudos sobre a relação adquirida entre as sociedades e o meio em que vivem para que a própria cultura destas populações não seja esquecida. Nesse sentido, a etnobotânica vem como um campo interdisciplinar que estuda o conhecimento, o significado cultural e os usos tradicionais dos elementos da flora (Freitas et al. 2012). Aplicar estes estudos as plantas medicinais, para desta forma elucidar para os próprios comunitários a importância deste saber, é uma forma de manter viva a cultura e melhorar a qualidade de vida e saúde das comunidades ribeirinhas.

\section{MATERIAL E MÉTODOS}

O questionário etnobotânico foi aplicado em outubro de 2015 na comunidade de várzea Igarapé do Costa, que faz parte do Projeto de Assentamento Extrativista (PAE)
Urucurituba, e é situada entre as coordenadas $02^{\circ} 15^{\prime} \mathrm{Sul}$ e 54³8' Oeste (Figura 1), localizada na bacia hidrográfica do rio Amazonas, de águas brancas, em planície fluvial pertencente a Santarém, sendo que a comunidade fica a cerca de $20 \mathrm{~km}$ de distância do porto desta cidade. O clima é quente e úmido, característico da região amazônica (Fisch et al. 1998). A vegetação é composta, principalmente, por contato entre savana e floresta ombrófila densa (SOc/Pahs+Sps) e vegetação fluvial herbácea (Dau) (Mapa de Vegetação da Amazônia 2002) (Figura 2.a). Os solos são do tipo neossolo flúvico Tb eutrófico, que são solos que ocorrem geralmente perto de rios ou drenagens de relevo plano, como é o caso das regiões de várzea (Miranda 2005) (Figura 2.b).

A comunidade Igarapé do Costa conta com uma Unidade Básica de Saúde (Figura 3), recentemente reformada e inaugurada e que conta com enfermeiros e técnicos, sendo estes, moradores da própria comunidade. Esta Unidade deve oferecer educação em saúde, vacinação, coletas para exames laboratoriais, teste do pezinho, curativos e coleta de exames de Prevenção ao Câncer do Colo Uterino (PCCU) e beneficiar mais de 500 famílias de comunidades vizinhas ao Igarapé do Costa (Prefeitura Municipal de Santarém 2016). Porém as visitas de médicos à comunidade são poucas e o material necessário para realizar estes procedimentos nem sempre são repassados pela prefeitura de Santarém. Para problemas emergenciais e de maior gravidade, os moradores devem deslocar-se à Santarém para receberem cuidados apropriados, deslocamento este que dura aproximadamente duas horas.

A comunidade possui cerca de 70 famílias, das quais se utilizou uma amostra de $35 \%$ das famílias para a realização da pesquisa, valor considerado significativo. As famílias foram selecionadas segundo avaliação qualitativa do líder da comunidade, que acompanhava o projeto e foi responsável pela locomoção de canoa de uma residência a outra, porém, para a aplicação do questionário, foi dado preferência aos membros mais velhos de cada uma destas residências. Foram entrevistadas 24 pessoas no total, aos quais foi entregue o termo de anuência, onde constavam os objetivos e metodologias da pesquisa, para devida assinatura do entrevistado, e logo em seguida aplicado o questionário.

Foi utilizado um método de entrevista semiestruturada, onde se utilizam perguntas abertas e fechadas, para que tanto o entrevistado possa discorrer sobre o tema quanto o entrevistador possa realizar uma conversa mais informal, mesmo que seguindo as questões pré-estabelecidas (Boni \& Quaresma 2005). As principais vantagens desse tipo de abordagem são que o entrevistador tem uma relação muito 
mais próxima com o entrevistado, além de que, esse tipo de entrevista pode ser aplicado a pessoas alfabetizadas e não alfabetizadas, levando-se em conta que o analfabetismo é uma realidade nas comunidades rurais.

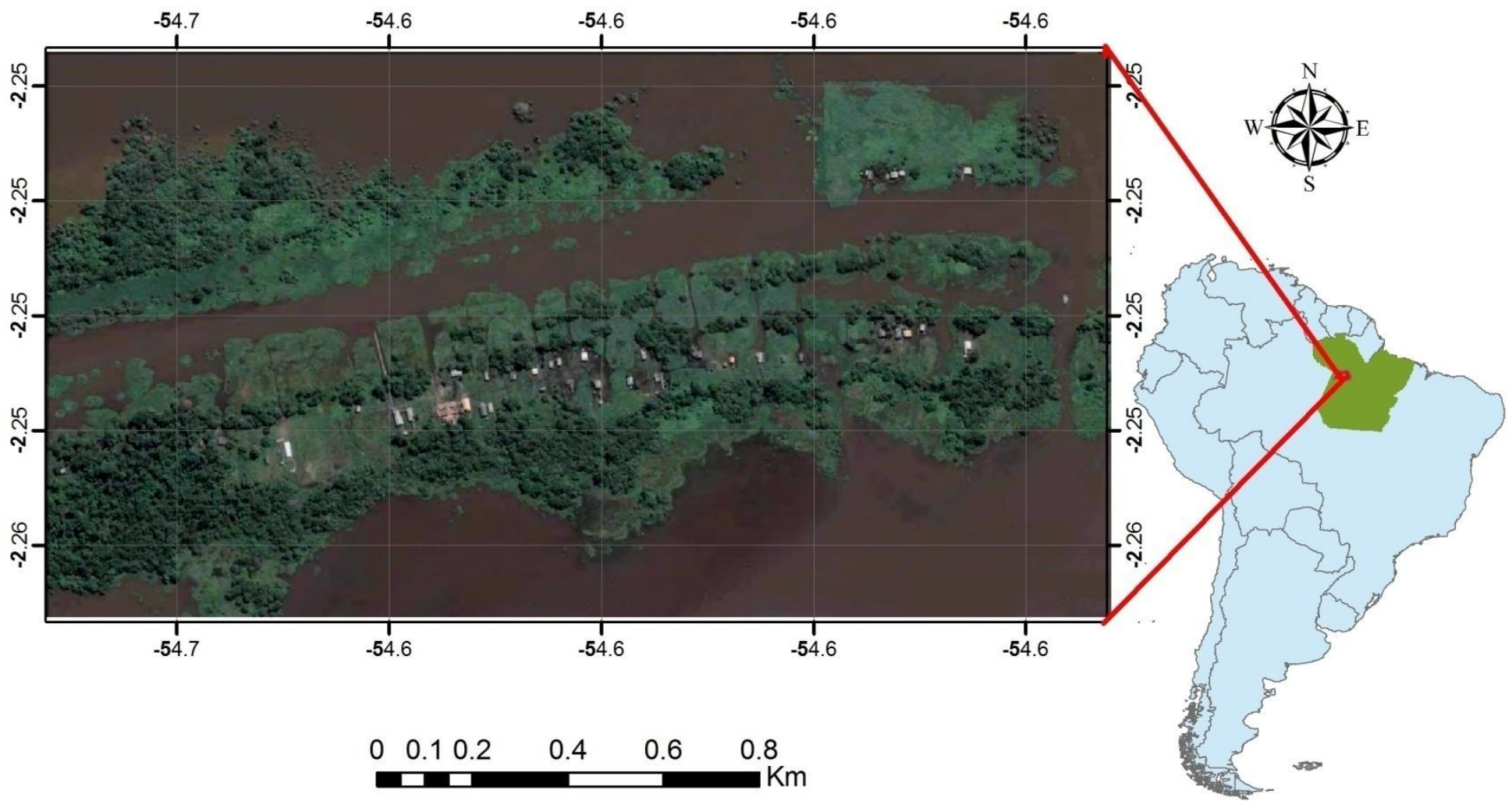

Figura 1. Mapa de Localização da Comunidade Igarapé do Costa (Fonte: Adaptado de LANDSAT, sensor OLI, capturado en agosto de 2015)

O formulário continha questões sobre aspectos pessoais, sociais e econômicos (nome, idade, sexo, profissão, escolaridade e tempo na comunidade), e sobre o conhecimento e uso de plantas medicinais (nome popular, formas de uso e partes utilizadas). Neste trabalho, foi considerando tanto plantas com uso para doenças conhecidas e tratadas pela medicina, quanto as indicadas para doenças culturais como panemisse (condição em que o indivíduo se encontra azarado, sem sorte), olho gordo etc.

Os resultados advindos dos questionamentos socioeconômicos foram listados em gráficos de pizza para uma melhor visualização, utilizando o software R. Aos dados do questionário etnobotânico foram aplicados Estatística Descritiva do software BioEstat versão 5.0 e os resultados foram representados em gráficos barras simples, utilizando o software R e a ferramenta gráficos do Excel.

Os índices calculados para análise etnobotânica foram:
1. Frequência relativa de citação (FRC): serve para identificar as espécies mais conhecidas ou mais utilizadas pela comunidade cuja formula é FRC= FC/N, onde FC é o número de informantes que mencionou o uso da espécie e $\mathrm{N}$ é o número total de informantes.

2. Valor de Uso: avalia a importância de uma espécie. Sua fórmula é $\mathbf{V U}=(\boldsymbol{V} \mathbf{U}) / \mathbf{N}$, onde o $\Sigma U$ é o somatório do número de usos de uma dada espécie mencionada pelo informante e $\mathrm{N}$ é o número total de informantes.

3. Nível de Fidelidade: avalia a importância da espécie baseada no consenso dos informantes para uma indicação terapêutica principal em meio as mais variadas indicações terapêuticas informadas. A fórmula é $\mathbf{F L}=(\mathrm{IP} / \mathrm{IU}) \times \mathbf{1 0 0} \%$, em que IP é o número de informantes que citaram o uso principal da espécie e IU é o número total de informantes que 
citaram a espécie para qualquer finalidade (Cavalcante 2014).

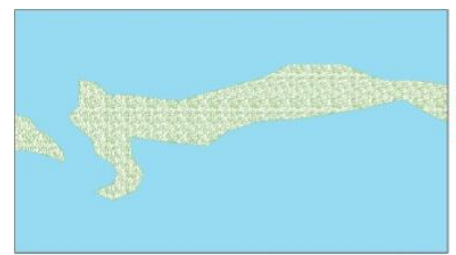

(a) Mapa de tipo de vegetação

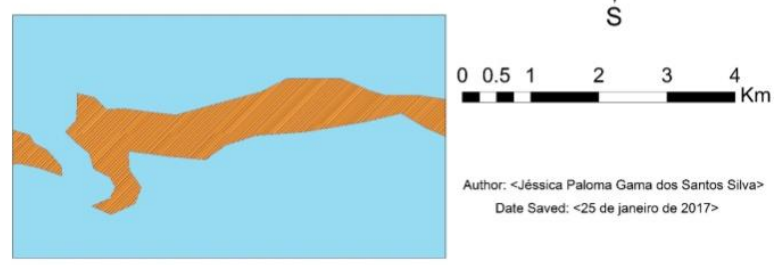

(b) Mapa de tipo de solo

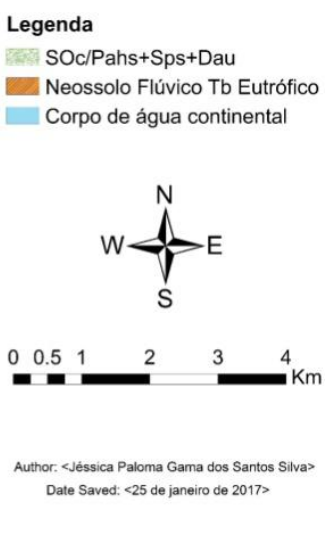

SOc/Pahs+Sps+Dau

Neossolo Flúvico Tb Eutrófico

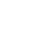

(1)

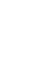

Figura 2: (a) Mapa de tipo de vegetação da comunidade Igarapé do Costa (Fonte: adaptado de INPE). (b) Mapa de tipo de solo da comunidade Igarapé do Costa (Fonte: Adaptado de Miranda 2005).

\section{RESULTADOS E DISCUSSÃO}

\section{Perfil socioeconômico dos entrevistados}

Foram entrevistadas 24 pessoas, com idades que variam de 26 a 77 anos, porém as faixas de idade mais representativas foram as de 25 a 35 e 46 a 55 anos, com $37,5 \%$ e 33,33\%, respectivamente (Figura 4. Idade). A presença massiva de entrevistados com idade abaixo de 55 anos pode ser por conta de a formação de famílias começar cedo em comunidades mais afastadas dos centros urbanos. E a baixa representatividade de entrevistados na faixa de idade de 66 a 80 anos, que é esperado que seja maior, deve ocorrer, por conta do êxodo destas pessoas mais velhas para a cidade em busca de cuidados com a saúde, muitas vezes levados pelos próprios filhos que já evadiram para as cidades. Já o sexo prevalecente nos entrevistados foi o feminino, com $92 \%$ contra $8 \%$ do sexo masculino (Figura 4 . Sexo), sendo esta percentagem premeditada jáque as mulheres foram o alvo principal da pesquisa, pois é preconizado que as mulheres, principalmente as mais velhas, são as maiores detentoras do saber sobre plantas medicinais (Menezes 2009).

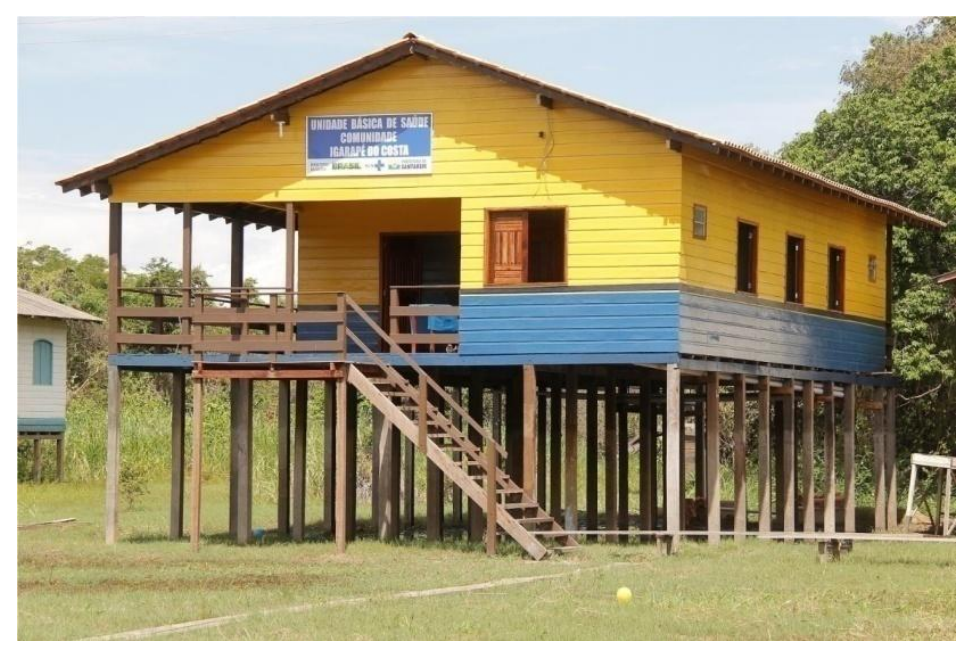

Figura 3: Unidade Básica de Saúde da comunidade de várzea Igarapé do Costa (Fonte: William Santos. CCOMPMS).

$33,34 \%$ dos entrevistados possuem apenas o ensino fundamental incompleto como grau de escolaridade e 12,5\% são analfabetos (Figura 4. Escolaridade), sendo que os analfabetos entrevistados eram mulheres e mais velhas, já que não haviam escolas na comunidade antigamente e estas não puderam migrar para os centros urbanos para estudar por conta das condições financeiras e/ou por que tinham que trabalhar para colaborar com a família. A comunidade possui apenas uma escola municipal de ensino fundamental e o ensino médio deve ser feito ou na área urbana de Santarém ou pelo ensino modular, que é a visita periódica de professores a comunidade para dar aulas. A grande maioria dos entrevistados, também, reside a comunidade a vida toda (75\%) (Figura 4. Tempo na Comunidade), colaborando com o conhecimento das plantas específicas da região.

A profissão de pescador é a que possui maior representatividade (67\%) (Figura 4. Profissão), pelo fato de tratar-se de uma comunidade ribeirinha e de várzea, com vasta variedade de peixes que abastecem as suas mesas e os mercados da cidade de Santarém, sendo esta a principal fonte de renda. Esta profissão é desempenhada tanto por homens quanto por mulheres, não sendo restrita a um único sexo. E por tratar-se de uma comunidade com liderança estabelecida e forte, o período de defeso é superado pelo seguro defeso que é uma política estratégica que visa proteger as espécies no seu período de reprodução, porém, mantendo uma renda de subsistência aos pescadores (Gouveia et al. 2015). Porém, é conhecido que a comunidade exerce outras atividades produtivas, como a pecuária e a agricultura. Estas atividades são realizadas principalmente na época da seca, quando o gado pode pastar em terra firma 
e quando é possível cultivar o solo da região. Acredita-se que por conta de o questionário ter sido aplicado no período de cheia essas atividades estavam mais esquecidas pelos entrevistados ou eles realmente não praticam essas atividades.

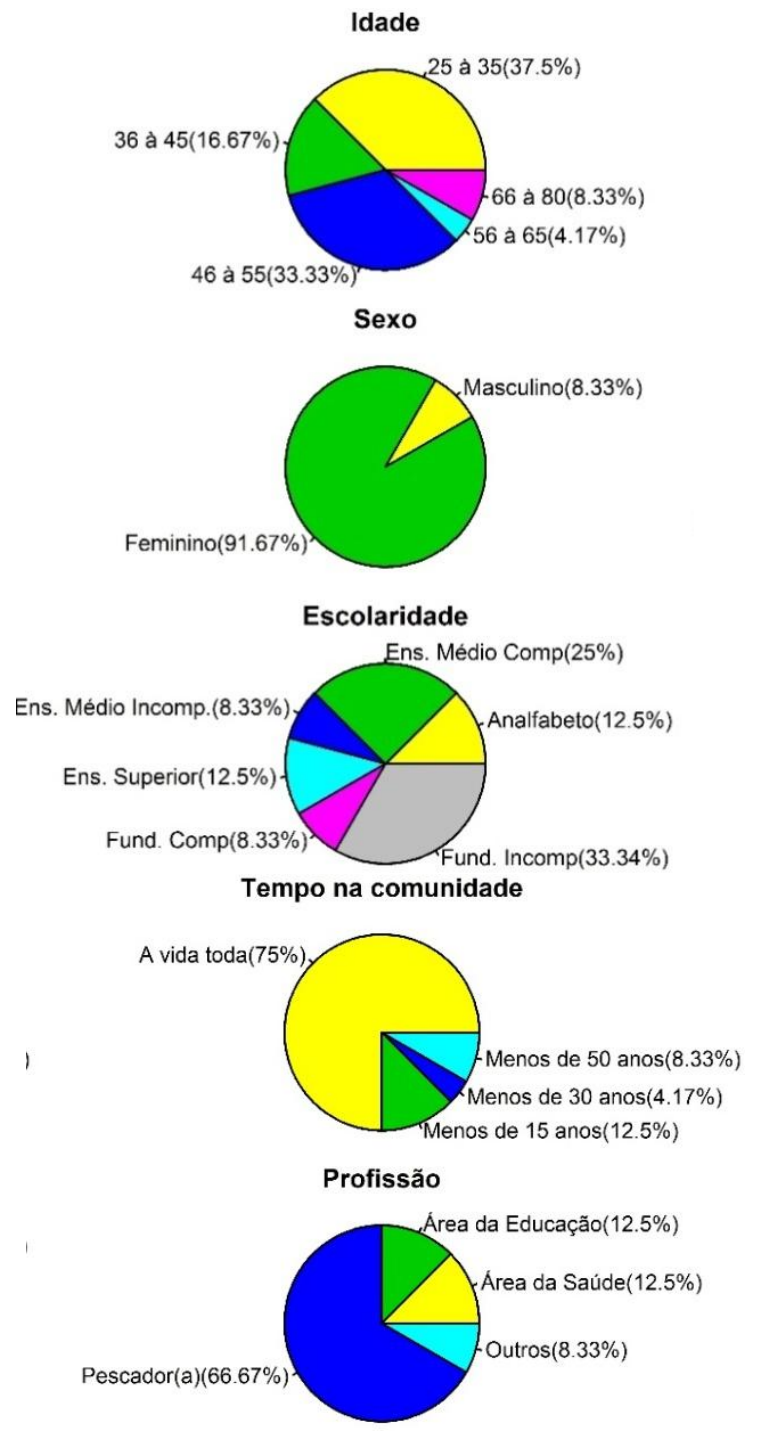

Figura 4. Perfil socioeconômico dos entrevistados da comunidade de Igarapé do Costa. Idade; Tempo na Comunidade; Sexo; Profissão; Escolaridade.

\section{Dados etnobotânicos e estatísticas}

A questão da renda familiar não teve respostas concretas, pois os entrevistados não possuem certeza do quanto arrecadam mensalmente, e este tópico foi desconsiderando nas entrevistas, porém, foi possível caracterizar essa comunidade em uma classe de renda baixa.

As famílias com maiores contribuições do conhecimento sobre plantas medicinais foram 24 e 3 (Gráfico 1), respectivamente, sendo que a representante da família 24 foi a entrevistada mais velha, com 77 anos. Tanto a entrevistada da família 24 quanto a entrevistada da família 3, de 45 anos, relatam a necessidade frequente de uso de remédios caseiros, principalmente para o uso em problemas de saúde das crianças. Ambas sempre viveram na comunidade, o que lhes confere conhecimento sobre as plantas existentes e adaptadas a sua região. Ressalta-se a importância de se realizar pesquisas mais abrangentes, que abarquem a maior parte da comunidade. Porém, a dificuldade de acesso nas comunidades rurais em geral não deve servir como impeditivo da realização de pesquisas etnobotânicas nestas áreas. Por isso, mesmo a não tão alta taxa de entrevistados neste trabalho ainda é muito importante para o reconhecimento e preservação do conhecimento tradicional de plantas medicinais.

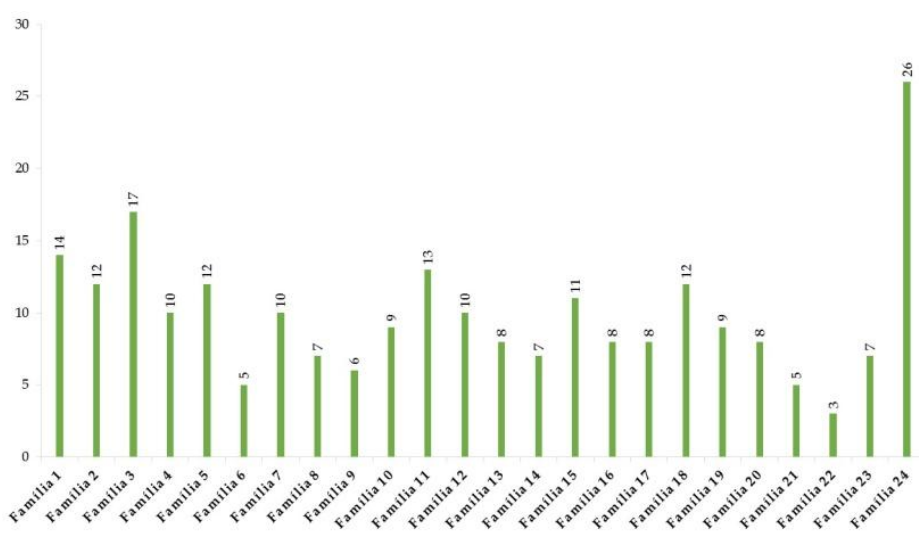

Gráfico 1. Número de plantas citadas pelos entrevistados representantes das famílias em Igarapé do Costa, Santarém, Pará, Brasil.

Os informantes mencionaram 58 espécies vegetais usadas para 21 tipos de doenças (Anexos), indicando um ou mais usos e formas de preparo. Uma parte destas espécies é encontrada na própria comunidade, e crescem de forma espontânea neste habitat, porém uma outra parte só cresce se cultivada em girais (canteiros elevados), nos quintais das casas. A indisponibilidade de grande parte destas plantas não tornou possível que se definisse a taxonomia de todas estas espécies, além da dificuldade de acesso que o ecossistema impõe para a pesquisa. Porém, a diversidade de trabalhos em etnobotânica na região permite que a consulta na literatura e comparação com os usos citados seja um instrumento para fazer o reconhecimento dos gêneros e espécies.

A parte mais utilizada das plantas foi a folha, seguida pela raiz, pela resina e pela casca. Maria Corette Pasa, em sua pesquisa etnobotânica realizada em Cuiabá, Mato Grosso, 
Brasil em 2011, diz que a preferência das folhas no preparo dos remédios é um costume que mostra os cuidados com a preservação dos recursos naturais. A forma de preparo mais citada foi o chá preparado a partir das folhas, mas também de outras partes da planta. Xaropes, emplastos, banhos e compressas representam outras formas de preparo citadas.

A frequência relativa de citações dada por $\mathrm{FRC}=\mathrm{FC} / \mathrm{N}$ é apresentada no Gráfico 2. As espécies com maior número de citações foram: Folha-grossa (Plectranthus amboinicus (Lour.) Spreng), Cidreira (Lippia alba (Mill.) N. E. Br.), Arruda (Ruta graveolens), Cumarú (Dipteryx odorata (Aubl.) Willd) e Saratudo (Justicia acuminatissima (Miq.) Bremek.). A folha-grossa é uma planta muito utilizada pelos moradores da comunidade para doenças do trato respiratório e "vermelha" (que são inflamações ou inchaços musculares causados por baques muito fortes). A folha grossa também foi a mais citada no trabalho de Schultz (2015), realizado na comunidade quilombola Tiningú, Santarém, Pará, Brasil, e a cidreira foi a mais citada no trabalho de Leite (2015), realizado em comunidades rurais do município de Santarém, mostrando que o conhecimento tradicional na região amazônica possui certa uniformidade e que algumas plantas medicinais estão melhores estabelecidas do que outras.

A tabela 1 mostra que a frequência relativa de citação de plantas medicinais da comunidade de Igarapé do Costa variou entre 0.0417 e 0.7083 e obteve coeficiente de variação de $88.69 \%$ o que nos sugere que a maioria das plantas foi citada poucas vezes e uma pequena percentagem foram citadas muitas vezes, por isso a grande variação. Isto pode ser explicado pela pequena quantidade de plantas citadas por alguns entrevistados, ou seja, algumas pessoas conhecem mais plantas medicinais do que outras, elucidando que este não é um saber uniformemente difundido dentro da comunidade.

O valor de uso das plantas não está necessariamente atrelado a frequência relativa de citação, porém, quanto mais citada uma planta mais fácil será de encontrar formas de uso diferentes. Neste caso, o valor de uso não foi utilizado para caracterizar diversidades de uso em geral (como por exemplo: alimentar, ornamental, construção etc.), mas sim para distinguir a diversidade de indicações terapêuticas citadas para cada espécie (Gráfico 3). As espécies com maior valor de uso são, respectivamente, Plectranthus amboinicus, Justicia acuminatissima, Lippia alba, Eupatorium triplinerve, Ruta graveolens, Luffa operculata, Cymbopogon citratus, Zingiber officinale, Chenopodium ambrosioides, Piper callosum e Alternanthera brasiliana. No trabalho de Vasques et al. (2014), realizado no município de Manacapurú, Amazonas, Brasil, as espécies Plectranthus amboinicus, Lippia alba, Ruta graveolens e Cymbopogon citratus também obtiveram os maiores valores de uso, estabelecendo o valor regional e fortalecendo a certeza de uma potencialidade medicinal destas plantas, fazendo com que estas possam vir a ser os principais alvos em pesquisas farmacológicas na região norte do Brasil.

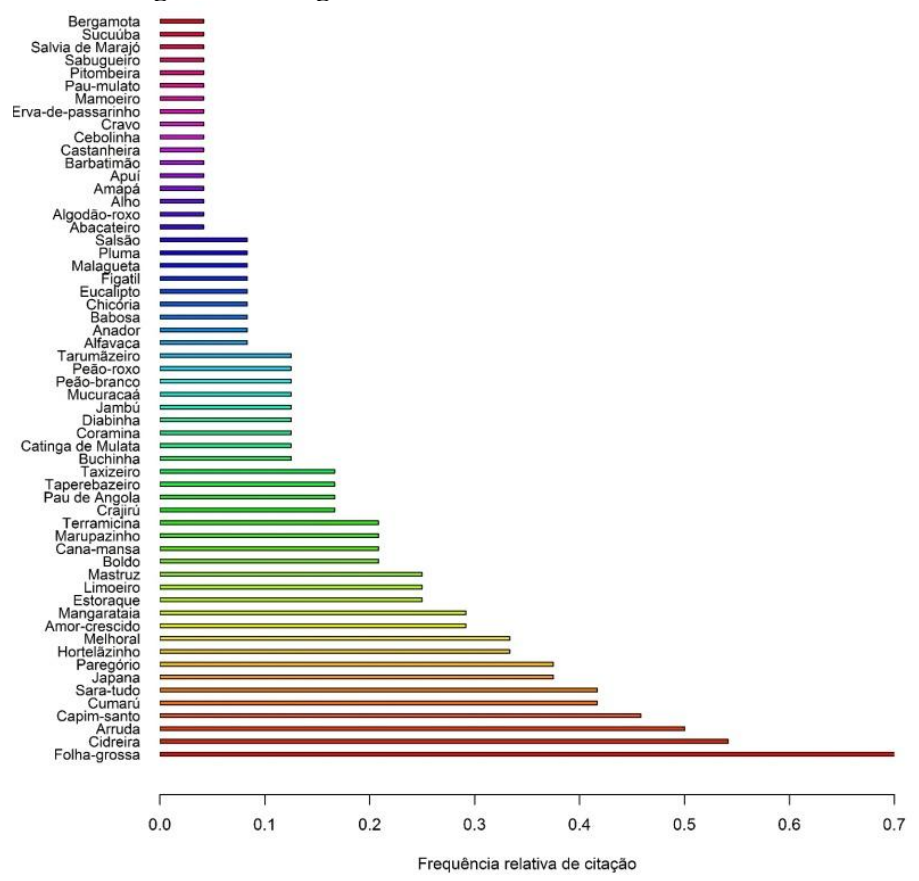

Gráfico 2. Frequência Relativa de Citações $(\mathrm{FRC}=\mathrm{FC} / \mathrm{N})$ de plantas medicinais citadas pelos comunitários de Igarapé do Costa, Santarém, Pará, Brasil.

Tabela 1: Resultados da análise de estatística descritiva acerca da Frequência Relativa de Citações $(F R C=F C / N)$ de plantas medicinais da comunidade de Igarapé do Costa, Santarém, Pará, Brasil.

\begin{tabular}{lc}
\hline Tamanho da Amostra & 58 \\
Mínimo & 0.04 \\
Máximo & 0.70 \\
Amplitude Total & 0.66 \\
Média Aritmética & 0.17 \\
Variância & 0.02 \\
Desvio Padrão & 0.14 \\
Coeficiente de Variação & $88.69 \%$ \\
\hline
\end{tabular}

$\mathrm{O}$ valor de uso das espécies medicinais citadas pelos entrevistados variou de 0.417 a 0.2917 e coeficiente de variação $59.93 \%$ (Tabela 2). Apesar de ser menos gritante, a variação ainda é alta e indica que algumas espécies são mais importantes ou mais conhecidas pela comunidade do que outras. Das 58 espécies citadas apenas 36 foram aludidas para mais de uma indicação terapêutica, o que indica a baixa popularidade de usos para estas plantas na comunidade. 


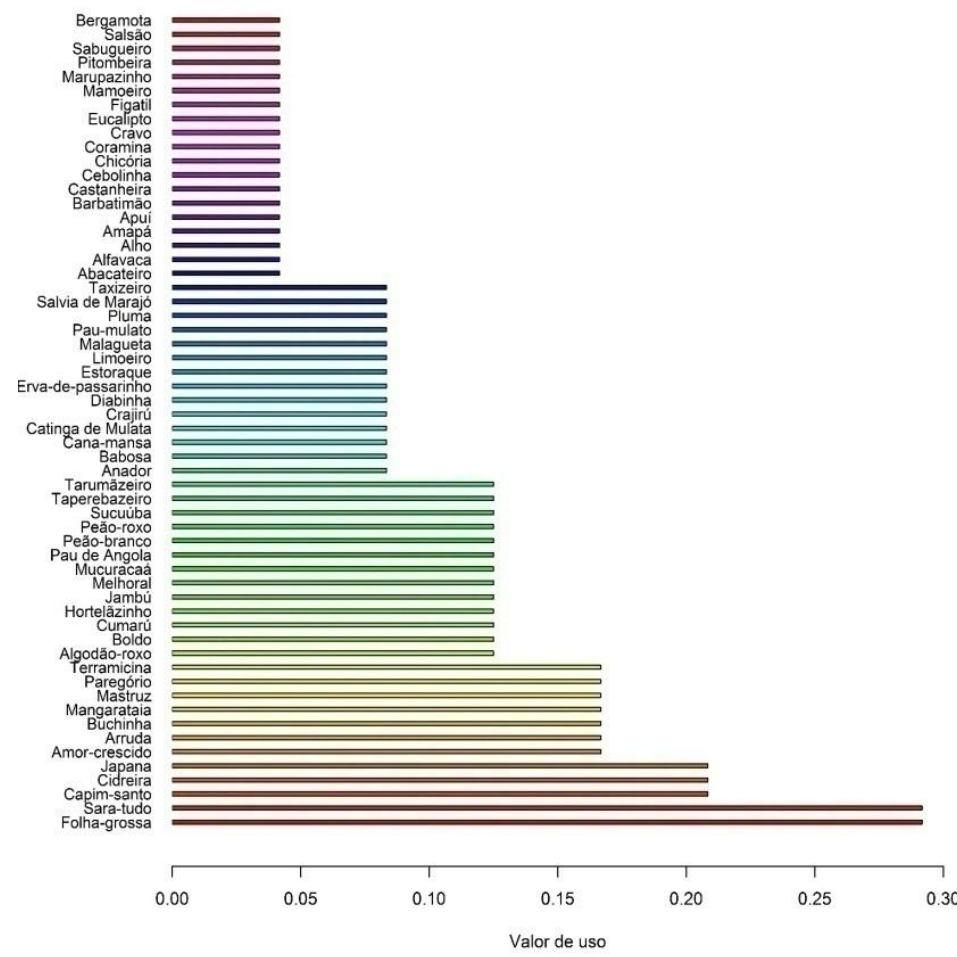

Gráfico 3: Valor de Uso $(\mathrm{VU}=(\Sigma \mathrm{U} / \mathrm{N}))$ de plantas medicinais citadas pelos comunitários de Igarapé do Costa, Santarém, Pará, Brasil.

Tabela 2: Resultados da análise de estatística descritiva acerca do Valor de Uso $(\mathrm{VU}=(\Sigma \mathrm{U} / \mathrm{N}))$ de plantas medicinais da comunidade de Igarapé do Costa, Santarém, Pará, Brasil.

\begin{tabular}{lc}
\hline Tamanho da Amostra & 58 \\
Mínimo & 0.04 \\
Máximo & 0.29 \\
Amplitude Total & 0.25 \\
Média Aritmética & 0.10 \\
Variância & 0.00 \\
Desvio Padrão & 0.06 \\
Coeficiente de Variação & $59.93 \%$ \\
\hline
\end{tabular}

O nível de Fidelidade só foi considerado para espécies citadas mais de uma vez (Gráfico 4). Das 41 espécies 14 obtiveram 100\% de FL, 22 das espécies citadas obtiveram de $50 \%$ a $90 \%$ de FL, e 5 obtiveram de $20 \%$ a $40 \%$ de FL. As espécies com nível de fidelidade de $100 \%$ foram, na maioria, pouco citadas (Tabela 3).

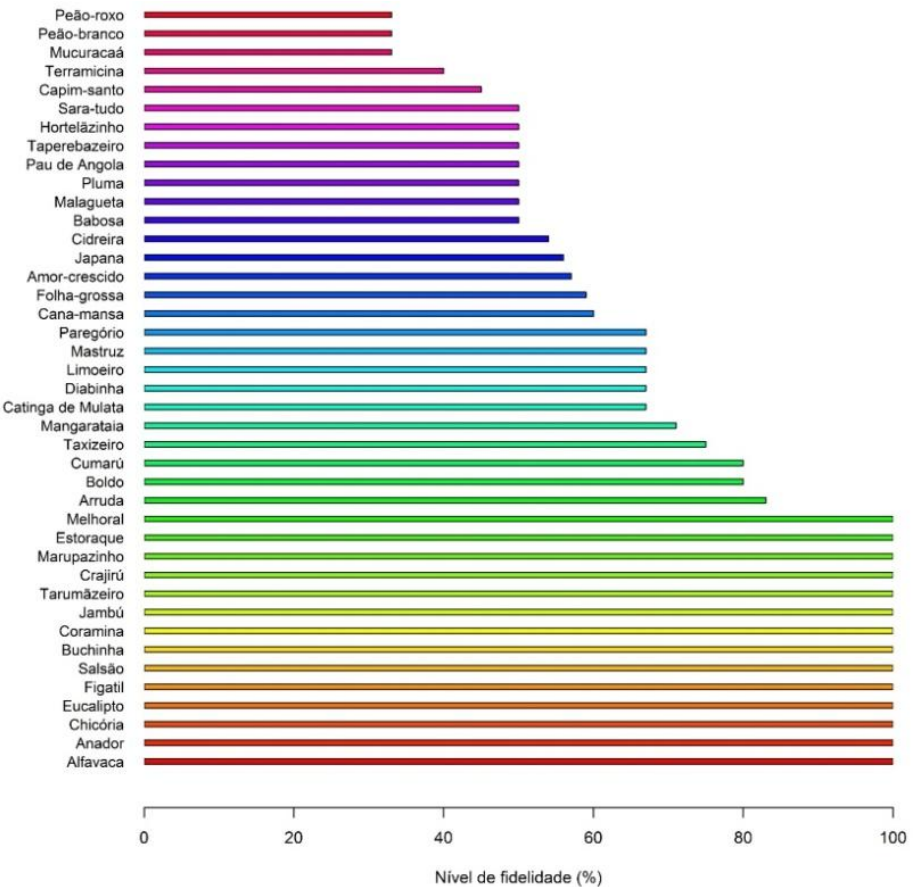

Gráfico 4. Nível de Fidelidade $(\mathrm{FL}=(\mathrm{Ip} / \mathrm{Iu}) \times 100 \%)$ de indicações terapêuticas das plantas medicinais citadas mais de uma vez pelos entrevistados em Igarapé do Costa, Santarém, Pará, Brasil.

Tabela 3. Resultados da análise de estatística descritiva acerca do Nível de Fidelidade $(\mathrm{FL}=(\mathrm{Ip} / \mathrm{Iu}) \times 100 \%)$ de plantas medicinais citadas mais de uma vez da comunidade de Igarapé do Costa, Santarém, Pará, Brasil.

\begin{tabular}{lc}
\hline Tamanho da Amostra & 41 \\
Mínimo & 33.00 \\
Máximo & 100.00 \\
Amplitude Total & 67.00 \\
Média Aritmética & 71.80 \\
Variância & 554.50 \\
Desvio Padrão & 23.54 \\
Coeficiente de Variação & $32.79 \%$ \\
\hline
\end{tabular}

O Nível de Fidelidade de plantas medicinais da comunidade de Igarapé do Costa variou entre $20 \%$ a $100 \%$ com coeficiente de variação $33.81 \%$, sugerindo que, as plantas que foram citadas mais de uma vez, estão em um certo grau de consenso entre os entrevistados para a sua indicação terapêutica principal. 
Pôde-se perceber que as plantas medicinais não possuem um papel importante na comunidade Igarapé do Costa, já que não são tão consumidas e nem fazem parte da renda familiar destas pessoas. Por isso, é papel das universidades a salvaguarda e enaltecimento deste saber. Essa pesquisa etnobotânica faz parte de um projeto de extensão chamado "Horto medicinal em assentamento rural de várzea: comunidade do Igarapé do Costa" que visa, através do levantamento do conhecimento tradicional das plantas medicinais da comunidade Igarapé do Costa, a implantação de um horto medicinal elevado (adaptado ao regime de cheias e secas) que irá localizar-se junto a Unidade Básica de Saúde e que deverá atender a toda comunidade, sendo mantido pelos agentes da própria unidade. Este é um exemplo de retorno que pode ser oferecido às comunidades pela universidade pela participação e apoio às pesquisas. Ações como educação ambiental, produção de cartilhas etc. são também formas de garantir a preservação e o retorno deste conhecimento.

\section{CONCLUSÕES}

A produção de trabalhos etnobotânicos direcionados as plantas medicinais são de grande importância pois instiga a investigação das atividades tóxicas e farmacológicas das plantas medicinais, gerando conhecimento e possibilitando a compreensão das melhores formas de uso deste material vegetal. Além das investigações farmacológicas, investigações quanto a fisiologia das plantas é muito importante, principalmente em se tratando de regiões de várzea, onde a maioria das plantas vive sob estresse durante a cheia do rio amazonas.

As comunidades ribeirinhas das várzeas amazônicas são um rico repositório de conhecimento e cultura. A relação do homem com o rio, a fauna e a flora do ecossistema revela a importância de se realizar pesquisas etnobotânicas nestas comunidades. As plantas citadas revelam os principais problemas pelos quais eles são acometidos, que são os problemas respiratórios, provenientes da alta umidade do ar e problemas estomacais adquiridos por conta da deficiência no saneamento básico e qualidade da água consumida por eles.

Percebe-se que as várzeas ainda são locais pouco acessíveis para as políticas públicas, sendo o saneamento básico, a saúde e educação as menos visíveis a seus residentes. Portanto, é dever das universidades e pesquisadores inseridos no contexto da Amazônia garantir a sobrevivência da cultura e saber tradicional destas populações com vistas a trazer retornos e visibilidade para os moradores dos rios.

\section{AGRADECIMENTOS}

À orientação da professora dra. Patrícia Chaves de Oliveira, à Pró-reitoria de Extensão da Universidade Federal do Oeste do Pará pelo incentivo financeiro através da bolsa de extensão e aos comunitários de Igarapé do Costa, em especial.

\section{REFERÊNCIAS}

BONI, V. \& QUARESMA, S. J. 2005. Aprendendo a entrevistar: como fazer entrevistas em Ciências Sociais. Em Tese. 2(1):68-80. (Data de acesso: 29 de agosto de 2016). Disponível em: https://periodicos.ufsc.br/index.php/emtese/article/view /18027/16976

BRAGA, J. 2013. Etnobotânica e Ecofisiologia de vegetações em cenários indígenas na região do tapajós como indicadores de estudos de interação biosfera-atmosfera na Amazônia. Dissertação de Mestrado em Ciências na área de Recursos Naturais da Amazônia. Área de concentração: Interação biosfera atmosfera. Programa de Pós-Graduação em Recursos Naturais da Amazônia, Universidade Federal do Oeste do Pará-UFOPA, Santarém, Pará, Brasil. (Data de acesso: 15 de setembro de 2016). Disponível em: http://www.ufopa.edu.br/academico/pos-

graduacao/banco-de-teses/ppg-rna/turma-de-2011/bragajacqueline/at_download/file

CAVALCANTE, S. C. 2014. Ecossistema de Várzea: Etnobotânica e Ecofisiologia. Dissertação de Mestrado em Ciências Ambientais. Área de Concentração: Processos de Interação da Biosfera-Atmosfera na Amazônia -Programa de Pós-Graduação em Recursos Naturais da Amazônia. Universidade Federal do Oeste do Pará -UFOPA, Santarém, Pará, Brasil. (Data de acesso: 19 de setembro de 2016). Disponível em: http://www.ufopa.edu.br/academico/posgraduacao/banco-de-teses/ppg-rna/turma-de-

2012/cavalcante-suellen-castro/at_download/file

FIEBIG, G. A., \& PASA, M. C. 2016. A etnobotânica na comunidade Passagem da Conceição em Várzea Grande, Mato Grosso, Brasil. Biodiversidade. 15(2):101-123. (Data de acesso: 02 de janeiro de 2017). Disponível em: http://periodicoscientificos.ufmt.br/ojs/index.php/biodive rsidade/article/view/3964

FISCH, G., MARENGO, J. A., \& NOBRE, C. A. 1998. Uma revisão geral sobre o clima da Amazônia. Acta. Amazônica, 28(2):101-126. (Data de acesso: 21 de janeiro de 2017). 
Disponível

http:/ / www.scielo.br/scielo.php?pid=S0044-

59671998000200101\&script=sci_abstract\&tlng=pt

FREITAS, A. V. L., COELHO, M. D. F. B., MAIA, S. S. S., DE AZEVEDO, R. A. B. 2012. Plantas medicinais: um estudo etnobotânico nos quintais do Sítio Santa Cruz, São Miguel, Rio Grande do Norte, Brasil. Revista Brasileira de Biociências, 10(1):48. (Data de acesso 25 de agosto 2016). Disponível em: http://www.ufrgs.br/seerbio/ojs/index.php/rbb/article/ view $/ 1833$

GOUVEIA, N. A., LIMA, F. A., CASTRO SOUSA, M., SANTOS, M. A. S. 2015. O seguro defeso do pescador artesanal: evolução dos recursos e beneficiários no estado do Pará. Monografias Ambientais, 14(2):75-85. (Data de acesso 03 de setembro 2016). Disponível em: http: https://periodicos.ufsm.br/remoa/article/view/17881

GUIMARÃES, M. F. M. 2016. Plantas úteis em comunidades urbanas: a importância das espécies exóticas e do gênero na manutenção do conhecimento e uso dos recursos vegetais. Dissertação de Mestrado em Ecologia de Biomas Tropicais. Instituto de Ciências Exatas e Biológicas, Universidade Federal de Ouro Preto, Minas Gerais, Brasil. (Data de acesso: 20 de janeiro de 2017). Disponível em: http://www.repositorio.ufop.br/handle/123456789/7061

INSTITUTO DE PESQUISA AMBIENTAL DA AMAZÔNIA (IPAM), WWE-BRASIL. 2008. Testemunhas do Clima: Comunidade Igarapé do Costa - Várzea de Santarém, Pará. (Data de acesso: 10 de agosto de 2016). Disponível em: http://www.wwf.org.br/natureza_brasileira/reducao_de_i mpactos2/clima/clima_news/mudancas_especiais/testemu nhasdoclima/

JESUS, N. Z. T. D., LIMA, J. C. D. S., SILVA, R. M. D., ESPINOSA, M. M., \& MARTINS, D. T. D. O. 2009. Levantamento etnobotânico de plantas popularmente utilizadas como antiúlceras e antiinflamatórias pela comunidade de Pirizal, Nossa Senhora do Livramento-MT, Brasil. RevBrasFarmacogn, 19(1):130-9. (Data de acesso: 01 de setembro de 2016). Disponível em: http:/ / www.scielo.br/scielo.php?script=sci_arttext\&pid=S0 102-695X2009000100023

JUNIOR, V. F. V., PINTO, A. C., MACIEL, M. A. M. 2005. Plantas medicinais: cura segura. Química nova, 28(3):519528. (Data de Acesso: 07 de junho de 2016). Disponível em: http:/ / www.scielo.br/scielo.php?script=sci_arttext\&pid=S0 100-40422005000300026
LEITE. M. N. 2015. Etnobotânica e fisiologia do estresse em plantas medicinais. Dissertação de Mestrado em Ciências Ambientais. Área de Concentração: Estudos e manejos dos ecossistemas amazônicos. Programa de Pós-Graduação em Recursos Naturais da Amazônia. Universidade Federal do Oeste do Pará -UFOPA, Santarém, Pará, Brasil. (Data de acesso: 05 de agosto de 2016). Disponível em: https://sucupira.capes.gov.br/sucupira/public/consultas/ coleta/trabalhoConclusao/viewTrabalhoConclusao.jsf?pop up $=$ true\&id_trabalho $=3694013$

MAPA DE VEGETAÇÃO DA AMAZÔNIA. 2002. (Mapa de vegetação). AMBDATA - Variáveis Ambientais para Modelagem de Distribuição de Espécies. (Data de acesso: 20 de janeiro de 2017). Disponível em: http://www.dpi.inpe.br/Ambdata/mapa_sipam.php

MARTÍNEZ-RODRÍGUEZ, $\quad$ M. $\quad$ R. 2009. EthnobotanicalknowledgeacquisitionamongTsimane'childre $\mathrm{n}$ in the Bolivian Amazon. Tese de Doutorado. UniversityofGeorgia, Estados Unidos. (Data de acesso 22 de agosto 2016). Disponível em: http://athenaeum.libs.uga.edu/handle/10724/25884

MCDADE, T. W., REYES-GARCÍA, V., BLACKINTON, P., TANNER, S., HUANCA, T., LEONARD, W. R. 2007. Ethnobotanical knowledge is associated with indices of child health in the Bolivian Amazon. Proceedings of the National Academy of Sciences, 104(15): 6134-6139. (Data de acesso 22 de agosto 2016). Disponível em: https://www.ncbi.nlm.nih.gov/pubmed/17389376

MENEZES, S. 2009. Apoiadas pelo Iphan, comunidades fazem inventário de seus conhecimentos sobre as propriedades curativas das plantas. Retratos - Plantas Medicinais, Edição 55. (Data de acesso: 19 de dezembro de 2016). Disponível em: http:/ / www.ipea.gov.br/desafios/index.php?option=com content\&view $=$ article\&id=2295: catid=28\&Itemid $=23$

MINISTÉRIO DA SAÚDE. SECRETARIA DE CIÊNCIA, TECNOLOGIA E INSUMOS ESTRATÉGICOS. DEPARTAMENTO DE ASSISTÊNCIA FARMACÊUTICA E INSUMOS ESTRATÉGICOS. 2006a. A fitoterapia no SUS e o Programa de Pesquisa de Plantas Medicinais da Central de Medicamentos. Brasília, DF, Brasil. (Data de acesso 25 de agosto 2016). Disponível em: http://livroaberto.ibict.br/handle/1/558

MINISTÉRIO DA SAÚDE. SECRETARIA DE CIÊNCIA, TECNOLOGIA E INSUMOS ESTRATÉGICOS. DEPARTAMENTO DE ASSISTÊNCIA FARMACÊUTICA E INSUMOS ESTRATÉGICOS. 2006b. Política nacional de 
Ambiente y Sostenibilidad 2016 (6): 136-151

Revista del Doctorado Interinstitucional en Ciencias Ambientales

plantas medicinais e fitoterápicos.Brasília, DF, Brasil. (Data de acesso 25 de agosto 2016). Disponível em: bvsms.saude.gov.br/bvs/publicacoes/politica_nacional_fitoterapico s.pdf

MINISTÉRIO DA SAÚDE. SECRETARIA DE CIÊNCIA, TECNOLOGIA E INSUMOS ESTRATÉGICOS. DEPARTAMENTO DE ASSISTÊNCIA FARMACÊUTICA E INSUMOS ESTRATÉGICOS. 2009. Programa nacional de plantas medicinais e fitoterápicos. Brasília, DF, Brasil. (Data de acesso 25 de agosto 2016). Disponível em: http://livroaberto.ibict.br/handle/1/581

MIRANDA, E. E. de. 2005. Brasilem Relevo. Campinas: Embrapa Monitoramento por Satélite. (Data de acesso: 23 de janeiro de 2017). Disponível em: http://www.relevobr.cnpm.embrapa.br

MOURA, E. A. F. 2009. Indicadores ecossistêmicos de saúde na várzea amazônica. XXVII Congreso de laAsociaciónLatinoamericana de Sociología. VIII Jornadas de Sociología de laUniversidad de Buenos Aires. AsociaciónLatinoamericana de Sociología, Buenos Aires. (Data de acesso 15 de setembro de 2016). Disponível em: http://cdsa.aacademica.org/000-062/695

PASA, M. C. 2011. Local knowledgeandfolk medicine: ethnobotany in Cuiabá, Mato Grosso, Brazil. Boletim do Museu Paraense Emílio Goeldi. Ciências Humanas. 6(1):179196. (Data de acesso: 13 de agosto de 2016). Disponível em: http:/ / www.scielo.br/scielo.php?script=sci_arttext\&pid=S1 981-81222011000100011

PRANCE, G. T. 1980. A terminologia dos tipos de florestas amazônicas sujeitas à inundação. Acta. Amazônica, 10: 495504. (Data de acesso: 19 de agosto de 2016). Disponível em: https://acta.inpa.gov.br/fasciculos/10-

3/PDF/v10n3a05.pdf

PREFEITURA MUNICIPAL DE SANTARÉM. 2016. Santarém 355 anos: Prefeitura entrega a nova Unidade Básica de saúde da comunidade Igarapé do Costa. (Data de acesso: 18 de janeiro de 2016). Disponível em: http://www.santarem.pa.gov.br/conteudo/?item $=55 \& f a=1$ $\& c d=10329$

PRESIDÊNCIA DA REPÚBLICA DO BRASIL. Decreto $N^{\circ}$ 5.813, de 22 de junho de 2006, aprova a Política Nacional de Plantas Medicinais e Fitoterápicos e dá outras providências. (Casa Civil, Subchefia para Assuntos Jurídicos). (Data de acesso: 19 de agosto de 2016). Disponível em: http://www.planalto.gov.br/ccivil_03/_Ato2004-

2006/2006/Decreto/D5813.htm $\underset{\text { Digital }}{\text { ISSN: 2339-3122 }}$

PRESIDÊNCIA DA REPÚBLICA DO BRASIL. Decreto No 6.040, de 7 de fevereiro de 2007, institui a Política Nacional de Desenvolvimento Sustentável dos Povos e Comunidades Tradicionais. (Casa Civil, Subchefia para Assuntos Jurídicos). (Data de acesso: 19 de agosto de 2016). Disponível em: http://www.planalto.gov.br/ccivil_03/_ato20072010/2007/decreto/d6040.htm

RODRIGUES, A. P., \& ANDRADE, L. H. C. 2014. Levantamento etnobotânico das plantas medicinais utilizadas pela comunidade de Inhamã, Pernambuco, Nordeste do Brasil. Revista brasileira de plantas medicinais, 16(3):721-730. (Data de acesso: 12 de setembro de 2016). Disponível em: http://www.scielo.br/scielo.php?script=sci_abstract\&pid= S1516-05722014000700012\&lng=pt\&nrm=iso

ROMAN, A. L. C., MING, L. C., CARVALHO, I. D., SABLAYROLLES, M. D. G. P. 2011. Uso medicinal da pimenta malagueta (Capsicumfrutescens L.) em uma comunidade de várzea à margem do rio Amazonas, Santarém, Pará, Brasil. Boletim do Museu Paraense Emílio Goeldi. Ciências Humanas, 6(3):543-557. (Data de acesso: 05 de agosto de 2016). Disponível em: http:/ / www.scielo.br/scielo.php?script=sci_arttext\&pid=S1 981-81222011000300005

SCHULTZ, T. L. G. 2015. Etnofarmacologia e fisiologia de plantas medicinais do quilombo Tiningú, Santarém, Pará, Brasil. Dissertação de Mestrado em Ciências Ambientais. Área de Concentração: Estudos e manejos dos ecossistemas amazônicos. Programa de Pós-Graduação em Recursos Naturais da Amazônia. Universidade Federal do Oeste do Pará - UFOPA, Santarém, Pará, Brasil. (Data de acesso: 13 de setembro de 2016). Disponível em: https://sucupira.capes.gov.br/sucupira/public/consultas/ coleta/trabalhoConclusao/viewTrabalhoConclusao.jsf?pop up=true\&id_trabalho $=2589059$

SILVA, L. E., QUADROS, D. A., MARIA-NETO, A. J. 2015. Estudo etnobotânico e etnofarmacológico de plantas medicinais utilizadas na região de Matinhos-PR. Ciência e Natura. 37:266-276. (Data de acesso: 19 de setembro de 2016). Disponível em: https:// periodicos.ufsm.br/index.php/cienciaenatura/artic le/view/15473

SILVA, M. S.; FANTINI, A. C.; SHANLEY, P. 2011. Látex de amapá (Parahancorniafasciculata (Poir) Benoist, Apocynaceae): remédio e renda na floresta e na cidade. Boletim do Museu Paraense Emílio Goeldi. Ciências Humanas. 6(2):287-305. (Data de acesso: 19 de setembro de 2016).

Disponível

em: 
http:/ / www.cifor.org/library/3688/latex-de-amapaparahancornia-fasciculata-poir-benoist-apocynaceaeremedio-e-renda-na-floresta-e-na-cidade/

SILVA, R. M., FARIA, M. T., \& BUENO, A. U. 2014. Caracterização etnobotânica e histoquímica de plantas medicinais utilizadas pelos moradores do bairro Carrilho, Goianésia (GO). Enciclopédia Biosfera, Centro Científico Conhecer. 10(19):2807-2829. (Data de acesso: 01 de setembro de 2016). Disponível em: http://www.conhecer.org.br/enciclop/2014b/MULTIDISC IPLINAR/Caracterizacao\%20etnobotanica.pdf

VÁSQUEZ, S. P. F.; MENDONÇA, M. S.; NODA, S. do N. 2014. Etnobotânica de plantas medicinais em comunidades ribeirinhas do Município de Manacapuru, Amazonas, Brasil. Acta. Amazônica. 44(4):457-472. (Data de acesso: 15 de agosto de 2016). Disponível em: http:/ / www.scielo.br/scielo.php?script=sci_arttext\&pid=S0 044-59672014000400007

VIEIRA, V. M. S. F. 2012. Etnobotânica de plantas medicinais comercializadas em mercados públicos do nordeste brasileiro. Dissertação de Mestrado em Ciências Farmacêuticas. Universidade Federal do Ceará. Faculdade de Farmácia, Odontologia e Enfermagem, Fortaleza, Ceará, Brasil. (Data de acesso: 19 de setembro de 2016). Disponível em: http://www.repositorio.ufc.br/handle/riufc/4282 
Ambiente y Sostenibilidad 2016 (6): 136-151

\section{ANEXOS}

\begin{tabular}{|c|c|c|c|c|c|}
\hline Nome Popular & $\begin{array}{c}\text { Nome da espécie/ Família } \\
\text { botânica }\end{array}$ & Literatura & $\begin{array}{c}\text { Indicação } \\
\text { terapêutica }\end{array}$ & $\begin{array}{c}\text { Modo de preparo } \\
\text { e aplicação }\end{array}$ & $\begin{array}{c}\text { Partes } \\
\text { Utilizadas }\end{array}$ \\
\hline Abacateiro & Persea americana Mill. - Lauraceae & $\begin{array}{l}\text { Schultz } \\
2015\end{array}$ & Tosse & Chá & Folhas \\
\hline Alfavaca & $\begin{array}{l}\text { Ocimum gratissimum L. - } \\
\text { Lamiaceae }\end{array}$ & $\begin{array}{l}\text { Rodrigues } \\
\& \text { Andrade } \\
2014\end{array}$ & Problemas de visão & $\begin{array}{l}\text { Banho de cabeça, } \\
\text { lavar o rosto com } \\
\text { agua fria } \\
\text { contendo a planta }\end{array}$ & Folhas \\
\hline Algodão-roxo & Gossypium arboreum L. - Malvaceae & $\begin{array}{l}\text { Schultz } \\
2015\end{array}$ & $\begin{array}{l}\text { Infecção intestinal/ } \\
\text { Problemas } \\
\text { uterinos / cólica }\end{array}$ & Chá - Ingestão & Folhas \\
\hline Alho & Allium sativum L. - Liliaceae & $\begin{array}{l}\text { Schultz } \\
2015\end{array}$ & Tosse & Xarope & Raiz \\
\hline Amor-crescido & Portulaca pilosa L. - Portulacaceae & $\begin{array}{l}\text { Schultz } \\
2015\end{array}$ & $\begin{array}{l}\text { Problemas } \\
\text { estomacais/ } \\
\text { Diarreia/ } \\
\text { Problemas do } \\
\text { fígado/ Febre }\end{array}$ & Chá & Folhas \\
\hline Anador & $\begin{array}{l}\text { Justicia pectoralis Jacq. - } \\
\text { Acanthaceae }\end{array}$ & $\begin{array}{l}\text { Silva et al. } \\
2014\end{array}$ & $\begin{array}{l}\text { Calmante/ } \\
\text { Analgésico }\end{array}$ & Chá & Folhas \\
\hline Apuí & Ficus erratica Standl. - Moraceae & $\begin{array}{l}\text { Cavalcante } \\
2014\end{array}$ & Rasgadura & Emplasto & Leite \\
\hline Barbatimão & Dimorphandra mollis- Fabaceae & $\begin{array}{l}\text { Schultz } \\
2015\end{array}$ & $\begin{array}{l}\text { Inflamação do } \\
\text { útero }\end{array}$ & Chá & Folhas \\
\hline Bergamota & Citrus bergamia - Rutaceae & $\begin{array}{l}\text { Junior et al. } \\
2005\end{array}$ & Dor de Cabeça & Banho & Folhas \\
\hline Boldo & Peumus boldus Mol. - Monimiaceae & Vieira 2012 & $\begin{array}{l}\text { Problemas } \\
\text { estomacais/ } \\
\text { Enxaqueca/ } \\
\text { Problemas de } \\
\text { Fígado }\end{array}$ & Chá & Folhas \\
\hline Buchinha & $\begin{array}{l}\text { Luffa operculata(L.) Cogn. - } \\
\text { Cucurbitaceae }\end{array}$ & $\begin{array}{l}\text { Fiebig \& } \\
\text { Pasa } 2016\end{array}$ & $\begin{array}{l}\text { Sinusite/ Queda de } \\
\text { cabelo/ Abortivo }\end{array}$ & $\begin{array}{l}\text { Banho de cabeça/ } \\
\text { Chá/ Inalação }\end{array}$ & Cipó \\
\hline
\end{tabular}




\begin{tabular}{|c|c|c|c|c|c|}
\hline Nome Popular & $\begin{array}{c}\text { Nome da espécie/ Família } \\
\text { botânica }\end{array}$ & Literatura & $\begin{array}{l}\text { Indicação } \\
\text { terapêutica }\end{array}$ & $\begin{array}{c}\text { Modo de preparo } \\
\text { e aplicação }\end{array}$ & $\begin{array}{c}\text { Partes } \\
\text { Utilizadas }\end{array}$ \\
\hline Cana-mansa & $\begin{array}{l}\text { Costus spicatus (Jacq.) Sw. - } \\
\text { Zingiberaceae }\end{array}$ & $\begin{array}{l}\text { Schultz } \\
2015\end{array}$ & $\begin{array}{l}\text { Pedra nos rins/ } \\
\text { Infecção urinária }\end{array}$ & Chá & Folhas \\
\hline Capim-santo & $\begin{array}{l}\text { Cymbopogon citratus (DC.) Stapf. - } \\
\text { Poaceae }\end{array}$ & $\begin{array}{l}\text { Schultz } \\
2015\end{array}$ & $\begin{array}{l}\text { Problemas } \\
\text { estomacais/ } \\
\text { Calmante/ } \\
\text { Pressão/ } \\
\text { Hemorragia/ } \\
\text { Gases }\end{array}$ & Chá & Folhas \\
\hline Castanheira & $\begin{array}{l}\text { Bertholletia excelsa Bonpl. - } \\
\text { Lecythidaceae }\end{array}$ & $\begin{array}{l}\text { Schultz } \\
2015\end{array}$ & Coceira & Banho & Folhas \\
\hline $\begin{array}{l}\text { Catinga de } \\
\text { Mulata }\end{array}$ & Tanacetum vulgare- Asteraceae & $\begin{array}{l}\text { Silva et al. } \\
2015\end{array}$ & $\begin{array}{l}\text { Problemas } \\
\text { estomacais }\end{array}$ & Chá/ Banho & Folhas \\
\hline Cebolinha & Allium cepa L. - Liliaceae & $\begin{array}{l}\text { Schultz } \\
2015\end{array}$ & $\begin{array}{l}\text { Absorver veneno } \\
\text { de cobra }\end{array}$ & $\begin{array}{l}\text { Depositar sobre } \\
\text { mordida de cobra }\end{array}$ & Raiz \\
\hline Chicória & Eryngium foetidum L. - Apiaceae & Braga 2013 & Constipação & Chá & Folhas \\
\hline Cidreira & $\begin{array}{l}\text { Lippia alba (Mill.) N. E. Br. - } \\
\text { Verbenaceae }\end{array}$ & $\begin{array}{l}\text { Schultz } \\
2015\end{array}$ & $\begin{array}{l}\text { Pressão alta ou } \\
\text { baixa/ Problemas } \\
\text { estomacais/ } \\
\text { Calmante/ } \\
\text { Vômito/ Náuseas/ } \\
\text { Gripe }\end{array}$ & $\begin{array}{l}\text { Chá/ Inalação/ } \\
\text { Lavagem }\end{array}$ & Folhas \\
\hline Coramina & $\begin{array}{l}\text { Pedilanthus tithymaloides (L.) Poit. - } \\
\text { Euphorbiaceae }\end{array}$ & $\begin{array}{l}\text { Schultz } \\
2015\end{array}$ & $\begin{array}{l}\text { Problemas no } \\
\text { coração }\end{array}$ & Chá & Folhas \\
\hline Crajirú & $\begin{array}{l}\text { Friedericia chica (Humb. \&Bonpl.) } \\
\text { L. G. Lohmann - Bignoneaceae }\end{array}$ & $\begin{array}{l}\text { Schultz } \\
2015\end{array}$ & Anemia & Chá & Folhas \\
\hline Cravo & Tagetes erecta L. - Asteraceae & $\begin{array}{l}\text { Schultz } \\
2015\end{array}$ & AVC/ Derrame & Chá & Folhas \\
\hline Cumarú & $\begin{array}{l}\text { Dipteryx odorata (Aubl.) Willd - } \\
\text { Fabaceae }\end{array}$ & $\begin{array}{l}\text { Schultz } \\
2015\end{array}$ & $\begin{array}{l}\text { Tosse/ Inflamação } \\
\text { da garganta/ } \\
\text { Pneumonia/ } \\
\text { Afrouxar catarro }\end{array}$ & $\begin{array}{l}\text { Chá junto com } \\
\text { sara-tudo e jucá } \\
\text { ou Xarope }\end{array}$ & $\begin{array}{l}\text { Semente/ } \\
\text { Folhas }\end{array}$ \\
\hline Diabinha & $\begin{array}{l}\text { Harpagophytum procumbens DC. - } \\
\text { Pedaliaceae }\end{array}$ & Vieira 2012 & $\begin{array}{l}\text { Diarreia/ Infecção } \\
\text { estomacal }\end{array}$ & Chá & Folhas \\
\hline $\begin{array}{l}\text { Erva-de- } \\
\text { passarinho }\end{array}$ & Struthantus flexicaulis- Lorantaceae & $\begin{array}{l}\text { Schultz } \\
2015\end{array}$ & Reumatismo & Chá & Cipó \\
\hline Estoraque & $\begin{array}{l}\text { Ocimum micranthum Willd. - } \\
\text { Lamiaceae }\end{array}$ & $\begin{array}{l}\text { Schultz } \\
2015\end{array}$ & Tosse/ Gripe & Chá & Folhas \\
\hline Eucalipto & $\begin{array}{l}\text { Eucalyptus globulus Labill. - } \\
\text { Myrtaceae }\end{array}$ & $\begin{array}{l}\text { Schultz } \\
2015\end{array}$ & Febre & Chá & Folhas \\
\hline Figatil & $\begin{array}{l}\text { Vernonia condensata Baker - } \\
\text { Asteraceae }\end{array}$ & $\begin{array}{l}\text { de Jesus et } \\
\text { al. } 2009\end{array}$ & $\begin{array}{l}\text { Problemas de } \\
\text { Fígado }\end{array}$ & Chá & Folhas \\
\hline
\end{tabular}


Ambiente y Sostenibilidad 2016 (6): 136-151

Revista del Doctorado Interinstitucional en Ciencias Ambientales

ISSN: 2339-3122

Digital

\begin{tabular}{|c|c|c|c|c|c|}
\hline Nome Popular & $\begin{array}{c}\text { Nome da espécie/ Família } \\
\text { botânica }\end{array}$ & Literatura & $\begin{array}{l}\text { Indicação } \\
\text { terapêutica }\end{array}$ & $\begin{array}{c}\text { Modo de preparo } \\
\text { e aplicação }\end{array}$ & $\begin{array}{c}\text { Partes } \\
\text { Utilizadas }\end{array}$ \\
\hline Folha-grossa & $\begin{array}{l}\text { Plectranthus amboinicus (Lour.) } \\
\text { Spreng - Lamiaceae }\end{array}$ & $\begin{array}{l}\text { Schultz } \\
2015\end{array}$ & $\begin{array}{l}\text { Tosse/ Gripe/ } \\
\text { Inchaço/ Erisipela }\end{array}$ & Xarope/ Emplasto & Folhas \\
\hline Hortelãzinho & Mentha $x$ villosaHuds. - Lamiaceae & $\begin{array}{l}\text { Schultz } \\
2015\end{array}$ & Tosse/ Gases & Xarope/ Chá & \\
\hline Jambú & $\begin{array}{l}\text { Acmella oleracea (L.) R. K. Jansen - } \\
\text { Asteraceae }\end{array}$ & $\begin{array}{l}\text { Schultz } \\
2015\end{array}$ & $\begin{array}{l}\text { Problemas } \\
\text { estomacais/ } \\
\text { Enjoo/ Fastio }\end{array}$ & Chá & Folhas \\
\hline Japana & $\begin{array}{l}\text { Eupatorium triplinerve Vahl - } \\
\text { Asteraceae }\end{array}$ & $\begin{array}{l}\text { Schultz } \\
2015\end{array}$ & $\begin{array}{l}\text { Problemas } \\
\text { estomacais/ } \\
\text { Febre/ Inflamação } \\
\text { no útero/ Anemia/ } \\
\text { AVC }\end{array}$ & Chá & Folhas \\
\hline Limoeiro & Citrus limonum Risso - Rutaceae & $\begin{array}{l}\text { Schultz } \\
2015\end{array}$ & $\begin{array}{l}\text { Gripe / Picada de } \\
\text { cobra/ Febre }\end{array}$ & $\begin{array}{l}\text { Chá / Inalação/ } \\
\text { Banho de cabeça }\end{array}$ & $\begin{array}{l}\text { Folhas/ } \\
\text { Raiz }\end{array}$ \\
\hline Malagueta & Capsicum frutensens L. - Solanaceae & $\begin{array}{l}\text { Roman et } \\
\text { al. } 2011\end{array}$ & $\begin{array}{l}\text { Mau-olhado/ } \\
\text { Inflamação }\end{array}$ & Emplasto & $\begin{array}{l}\text { Fruto/ } \\
\text { Folhas }\end{array}$ \\
\hline Mamoeiro & Carica papaya L. - Caricaceae & $\begin{array}{l}\text { Schultz } \\
2015\end{array}$ & Picada de cobra & Chá & Raiz \\
\hline Mangarataia & $\begin{array}{l}\text { Zingiber officinale Roscoe - } \\
\text { Zingiberaceae }\end{array}$ & $\begin{array}{l}\text { Schultz } \\
2015\end{array}$ & $\begin{array}{l}\text { Tosse/ Inflamação } \\
\text { na Garganta/ } \\
\text { Gases/ Dor }\end{array}$ & Chá & Raiz \\
\hline Marupazinho & $\begin{array}{l}\text { Eleutherine bulbosa (Mill.) Urb - } \\
\text { Iridaceae }\end{array}$ & $\begin{array}{l}\text { Schultz } \\
2015\end{array}$ & Diarreia & Chá & Folha \\
\hline Mastruz & $\begin{array}{l}\text { Chenopodium ambrosioides L. - } \\
\text { Chenopodiaceae }\end{array}$ & $\begin{array}{l}\text { Schultz } \\
2015\end{array}$ & $\begin{array}{l}\text { Tosse/ Verme/ } \\
\text { Problemas } \\
\text { Pulmonares/ } \\
\text { Pneumonia }\end{array}$ & $\begin{array}{l}\text { Xarope do sumo/ } \\
\text { Bater no } \\
\text { liquidificado com } \\
\text { leite e ovo }\end{array}$ & Folhas \\
\hline Melhoral & Plectranthus barbatus - Lamiaceae & $\begin{array}{l}\text { Schultz } \\
2015\end{array}$ & Tosse & $\begin{array}{l}\text { Chá, Xarope e } \\
\text { Banho }\end{array}$ & Folha \\
\hline Mucuracaá & Petiveria alliacea L. - Phytolaccaceae & $\begin{array}{l}\text { Schultz } \\
2015\end{array}$ & $\begin{array}{l}\text { Panemisse/ } \\
\text { Problemas } \\
\text { Estomacais/ Mau- } \\
\text { olhado }\end{array}$ & $\begin{array}{l}\text { Banho de cabeça } \\
\text { para pescador/ } \\
\text { Chá }\end{array}$ & \\
\hline Paregório & $\begin{array}{l}\text { Piper callosum Ruiz \&Pav. - } \\
\text { Piperaceae }\end{array}$ & $\begin{array}{l}\text { Schultz } \\
2015\end{array}$ & $\begin{array}{l}\text { Problemas } \\
\text { estomacais/ } \\
\text { Vômito/ Gases }\end{array}$ & Chá & Folhas \\
\hline Pau de Angola & Piper divaricatum G. Mey. - Piperaceae & Schultz 2015 & $\begin{array}{l}\text { Panemisse/ mau- } \\
\text { olhado/ Problemas } \\
\text { estomacais }\end{array}$ & $\begin{array}{l}\text { Banho de cabeça } \\
\text { para pescador/ Chá }\end{array}$ & Folhas \\
\hline Pau-mulato & $\begin{array}{l}\text { Calycophyllum spruceanum (Benth.) } \\
\text { Hook.f. exK.Schum.- Rubiaceae }\end{array}$ & $\begin{array}{l}\text { Cavalvante } \\
2014\end{array}$ & $\begin{array}{l}\text { Infecções internas/ } \\
\text { Problemas de } \\
\text { próstata }\end{array}$ & Chá & Casca \\
\hline
\end{tabular}




\begin{tabular}{|c|c|c|c|c|c|}
\hline Nome Popular & $\begin{array}{c}\text { Nome da espécie/ Família } \\
\text { botânica }\end{array}$ & Literatura & $\begin{array}{c}\text { Indicação } \\
\text { terapêutica }\end{array}$ & $\begin{array}{c}\text { Modo de preparo } \\
\text { e aplicação }\end{array}$ & $\begin{array}{c}\text { Partes } \\
\text { Utilizadas } \\
\end{array}$ \\
\hline Peão-branco & Jatropha curcas L. - Euphorbiaceae & $\begin{array}{l}\text { Schultz } \\
2015\end{array}$ & $\begin{array}{l}\text { Inflamação/Ferida } \\
\text { na Boca/ } \\
\text { Panemisse }\end{array}$ & $\begin{array}{l}\text { Depositar o leite } \\
\text { sobre a } \\
\text { inflamação/ } \\
\text { Banho }\end{array}$ & $\begin{array}{l}\text { Folha e } \\
\text { Leite/ } \\
\text { Casca da } \\
\text { arvore }\end{array}$ \\
\hline Peão-roxo & $\begin{array}{l}\text { Jatropha gossypiifolia L. - } \\
\text { Euphorbiaceae }\end{array}$ & $\begin{array}{l}\text { Schultz } \\
2015\end{array}$ & $\begin{array}{l}\text { Problemas de } \\
\text { garganta/ } \\
\text { Antibiótico/ } \\
\text { Inchaço/ }\end{array}$ & $\begin{array}{l}\text { Ingestão do leite } \\
\text { com mel/ } \\
\text { Emplasto }\end{array}$ & $\begin{array}{l}\text { Leite da } \\
\text { Folha }\end{array}$ \\
\hline Pitombeira & $\begin{array}{l}\text { Talisia esculenta (A. St. - Hill.) } \\
\text { Radlk. - Sapindadeae }\end{array}$ & Vieira 2012 & Tosse & Xarope & $\begin{array}{l}\text { Folhas } \\
\text { novas }\end{array}$ \\
\hline Pluma & $\begin{array}{l}\text { Tetradenia riparia (Hochst.) Codd - } \\
\text { Lamiaceae }\end{array}$ & $\begin{array}{l}\text { Guimarães } \\
2016\end{array}$ & $\begin{array}{l}\text { Problemas } \\
\text { estomacais/ } \\
\text { Pneumonia }\end{array}$ & Chá & Folhas \\
\hline Sabugueiro & $\begin{array}{l}\text { Sambucus australis Cham. \&Schltdl. } \\
\text { - Adoxaceae }\end{array}$ & $\begin{array}{l}\text { Schultz } \\
2015\end{array}$ & Sarampo & Chá & Folhas \\
\hline Salsão & Apium graveolens L. - Annonaceae & $\begin{array}{l}\text { Guimarães } \\
2016\end{array}$ & Infecções & Emplasto & Cipó \\
\hline Salvia de Marajó & $\begin{array}{l}\text { Lippia salviifolia Cham. - } \\
\text { Verbenaceae }\end{array}$ & $\begin{array}{l}\text { Schultz } \\
2015\end{array}$ & $\begin{array}{l}\text { Inflamação } \\
\text { Uterina/ Cólica }\end{array}$ & Chá & Folhas \\
\hline Sara-tudo & $\begin{array}{l}\text { Justicia acuminatissima (Miq.) } \\
\text { Bremek. - Acanthaceae }\end{array}$ & $\begin{array}{l}\text { Schultz } \\
2015\end{array}$ & $\begin{array}{l}\text { Inflamação/ Dor/ } \\
\text { Problemas de } \\
\text { Garganta/ Infecção } \\
\text { Urinária/ } \\
\text { Corrimento }\end{array}$ & Chá e Xarope & Folhas \\
\hline Sucuúba & $\begin{array}{l}\text { Himatanthus ovalifolia- } \\
\text { Apocynaceae }\end{array}$ & $\begin{array}{l}\text { Schultz } \\
2015\end{array}$ & $\begin{array}{l}\text { Problemas } \\
\text { estomacais/ } \\
\text { Problemas no } \\
\text { útero/ Gastrite }\end{array}$ & Chá & $\begin{array}{l}\text { Leite da } \\
\text { casca }\end{array}$ \\
\hline Taperebazeiro & $\begin{array}{l}\text { Spondias mombin L. - } \\
\text { Anacardiaceae }\end{array}$ & $\begin{array}{l}\text { Schultz } \\
2015\end{array}$ & $\begin{array}{l}\text { Inflamação } \\
\text { uterina/ Asseio } \\
\text { feminino/ } \\
\text { Problemas de } \\
\text { Garganta }\end{array}$ & $\begin{array}{l}\text { Chá junto com a } \\
\text { casca do } \\
\text { Taxizeiro/ } \\
\text { Gargarejo }\end{array}$ & Casca \\
\hline Tarumãzeiro & $\begin{array}{l}\text { Vitex cymosa Berteroex Spreng. - } \\
\text { Lamiaceae }\end{array}$ & $\begin{array}{l}\text { Cavalcante } \\
2014\end{array}$ & Hepatite/ Malária & Chá & Folhas \\
\hline Taxizeiro & $\begin{array}{l}\text { Triplaris surinamensis Cham. - } \\
\text { Polygonaceae }\end{array}$ & $\begin{array}{l}\text { Cavalcante } \\
2014\end{array}$ & $\begin{array}{l}\text { Inflamação } \\
\text { uterina/ Aceito } \\
\text { feminino }\end{array}$ & $\begin{array}{l}\text { Chá junto com a } \\
\text { casca do } \\
\text { Taperebázeiro } \\
\text { para asseio }\end{array}$ & Casca \\
\hline Terramicina & $\begin{array}{l}\text { Alternanthera brasiliana (L) Kuntze. } \\
\text { - Amaranthaceae }\end{array}$ & $\begin{array}{l}\text { Schultz } \\
2015\end{array}$ & $\begin{array}{l}\text { Tosse/ Febre/ } \\
\text { Infecção }\end{array}$ & Xarope e chá & Folhas \\
\hline
\end{tabular}

